\title{
Faktor Risiko dan Luaran Maternal Plasenta Akreta di RSUP Dr. M. Djamil Padang
}

\author{
Annissa Qatrunnada, ${ }^{1}$ Puja Agung Antonius, ${ }^{2}$ Yusrawati $^{2}$ \\ ${ }^{1}$ Pendidikan Dokter Fakultas Kedokteran Universitas Andalas \\ ${ }^{2}$ Bagian Obstetri dan Ginekologi Fakultas Kedokteran Universitas Andalas \\ Korepondensi: Annissa Qatrunnada.Email: annisaqatrunnada02@gmail.com
}

\begin{abstract}
Abstrak
Tujuan: Penelitian ini bertujuan untuk mengetahui frekuensi kejadian, hubungan faktor risiko, dan luaran maternal dengan plasenta akreta.

Metode: Penelitian ini adalah analitik observasional dengan desain cross sectional. Penelitian dilakukan di bagian rekam medis RSUP Dr. M. Djamil Padang dari Januari 2016 sampai Desember 2017 dengan sampel penelitian berjumlah 84 orang yang terbagi dalam 2 kelompok, yaitu kelompok suspek plasenta akreta dan kelompok kontrol. Hasil: Hasil penelitian didapatkan sebanyak 64 orang $(4,3 \%)$ terdiagnosa suspek plasenta akreta. Terdapat hubungan yang bermakna antara usia, paritas, riwayat seksio sesarea, dan plasenta previa $(\mathrm{p}<0,05)$ dengan plasenta akreta. Didapatkan riwayat sectio cesarea $\geq 2$ kali merupakan faktor dominan pada plasenta akreta (OR 6,038, 95\% CI 2,145-16,995). Terdapat hubungan yang bermakna antara lama rawat $>7$ hari, butuh transfusi darah, dan histerektomi $(\mathrm{p}<0,05)$ dengan plasenta akreta.

Kesimpulan: Riwayat sectio cesarea, plasenta previa, usia, dan paritas merupakan faktor risiko plasenta akreta dengan morbiditas berupa lama rawat $>7$ hari, butuh transfusi darah, dan histerektomi.
\end{abstract}

Kata kunci: Plasenta akreta, seksio sesarea, plasenta previa

\section{Risk Factors and Maternal outcomes in Placenta Accreta in Dr. M. Djamil Padang General Hospital}

\begin{abstract}
Objective: This study aims to determine the frequency of occurrence, association of risk factors, and maternal outcomes with placenta accreta.

Method: This is an observational analytic with a cross-sectional design. This study was conducted in the medical record Dr. M. Djamil Padang General Hospital from January 2016 until December 2017 with total samples of the study were eighty four people and divided into 2 groups, suspected placenta accreta group and control group. Result: The result showed 64 people (4.3\%) were diagnosed with suspect placenta accreta. There were significant association between age, parity, prior cesarean section, and placenta previa $(p<0.05)$ with placenta accreta. The dominant factor in placenta accreta is $\geq 2$ prior cesarean section (OR 6,038, 95\% CI 2,145-16,995). There were significant association between length of stay more than 7 days, need blood transfusion, and hysterectomy $(p<0,05)$ with placenta accreta.

Conclusion: Prior cesarean section, placenta previa, maternal age, and parity are risk factors for placenta accreta with maternal morbidity such as length of hospital stay more than 7 days, requires blood transfusion, and hysterectomy.
\end{abstract}

Key words: Placenta accreta, cesarean section, placenta previa 


\section{Pendahuluan}

Sindrom plasenta akreta adalah sebuah kumpulan gejala yang menunjukkan adanya implantasi abnormal dari plasenta yang invasif atau adheren. Sindroma ini mencakup implantasi plasenta yang tertanam jauh ke miometrium karena tidak adanya sebagian atau seluruh desidua basalis dan terganggunya perkembangan lapisan Nitabuch. Berdasarkan kedalaman invasinya, sindrom plasenta akreta terbagi menjadi akreta, inkreta, dan perkreta. ${ }^{1,2}$ Akreta adalah kondisi vili korialis tertanam langsung pada miometrium, inkreta yaitu vili korialis menginvasi miometrium, dan perkreta saat vili korialis menembus miometrium hingga mengenai organ sekitar seperti kandung kemih. ${ }^{3}$

Kejadian plasenta akreta meningkat seiring meningkatnya kejadian seksio sesarea (SC). Berdasarkan beberapa penelitian yang telah dilakukan, plasenta akreta terjadi pada 1 dalam 2.500 kelahiran pada tahun 1980 . Angka kejadian ini semakin meningkat dari 1 dalam 535 kelahiran di tahun 2002 menjadi 1 dalam 210 kelahiran di tahun $2006 .{ }^{1}$ Plasenta akreta di India dilaporkan sebesar 4,3 per 10.000 kelahiran hidup. ${ }^{4}$ Plasenta akreta merupakan komplikasi obstetri yang dapat menyebabkan morbiditas dan mortalitas pada ibu. Dilaporkan angka morbiditas sebesar $60 \%$ dengan mortalitas sebesar $7 \% .^{5}$

Terdapat beberapa faktor risiko plasenta akreta, seperti riwayat SC, plasenta previa, in vitro fertilization (IVF), usia, paritas, riwayat kuretase, riwayat operasi uterus lainnya seperti miomektomi, merokok, Asherman's syndrome, dan hipertensi. Berdasarkan beberapa penelitian, riwayat SC dan plasenta previa merupakan faktor risiko yang sering ditemui pada plasenta akreta, sedangkan faktor risiko lainnya masih belum diketahui kontribusinya pada plasenta akreta. 6,2, 7,8

Penegakkan diagnosis dapat dilakukan melalui pemeriksaan ultrasonography (USG) dengan sensitivitas $77-87 \%$ dan spesifisitas $\quad 96-98 \% .^{9} \quad$ Placenta Accreta Index (PAI) merupakan sebuah prediktor untuk memperkirakan probabilitas terjadinya plasenta akreta dengan parameter pemeriksaan USG, yaitu riwayat $\mathrm{SC} \geq 2 \mathrm{kali}$, lakuna, ketebalan miometrium, plasenta previa anterior, dan bridging vessels. Semakin tinggi skor PAI, maka semakin tinggi kemungkinan ibu mengalami plasenta akreta. $^{8}$

Plasenta akreta dapat mengakibatkan perdarahan, baik intrapartum maupun postpartum. Histerektomi emergensi biasanya dilakukan pada plasenta akreta untuk menyelamatkan nyawa ibu. Penelitian ini bertujuan untuk mengetahui frekuensi kejadian, faktor risiko, dan luaran maternal plasenta akreta di RSUP Dr. M. Djamil Padang periode Januari 2016-Desember 2017.

\section{Metode}

Jenis penelitian ini adalah analitik observasional dengan pendekatan studi cross sectional. Penelitian di bagian Obstetri Ginekologi dengan data yang diambil dari rekam medis RSUP Dr. M. Djamil Padang. Populasi penelitian yaitu ibu hamil yang dirawat di bangsal Obstetri dan Ginekologi RSUP Dr. M. Djamil Padang periode Januari 2016-Desember 2017 dengan sampel penelitian yang memenuhi kriteria inklusi, yaitu ibu hamil yang terdiagnosa suspek plasenta akreta untuk kelompok kasus dan ibu hamil yang tidak terdiagnosa plasenta akreta untuk kelompok kontrol. Besar sampel minimal diperoleh menggunakan rumus analitik kategorik, sehingga didapatkan sebanyak 42 sampel untuk kelompok kasus dan 42 sampel untuk kelompok kontrol. Pengambilan sampel dilakukan dengan teknik konsekutif, yaitu semua sampel yang memenuhi kriteria dimasukkan ke dalam penelitian hingga sampel minimal tercukupi. Data diperoleh melalui data sekunder 
berupa rekam medis pasien. Faktor risiko yang diteliti yaitu usia, paritas, riwayat SC, plasenta previa, riwayat kuretase, dan riwayat operasi uterus lainnya (miomektomi). Luaran maternal yang diteliti yaitu lama rawatan $>7$ hari, butuh transfusi darah, butuh rawatan Intensive Care Unit (ICU), histerektomi, trauma buli, dan meninggal. Data dianalisis secara deskriptif untuk melihat frekuensi plasenta akreta, uji Chi-square untuk melihat hubungan variabel dependen dan independen, dan uji regresi logistik untuk melihat faktor risiko yang paling dominan.

\section{Hasil}

Berdasarkan hasil penelitian, didapatkan sebanyak 64 orang $(4,3 \%)$ dengan suspek plasenta akreta dari 1.491 ibu hamil yang dirawat di bangsal Obstetri dan Ginekologi RSUP Dr. M. Djamil Padang periode Januari 2016-Desember 2017.

Berdasarkan Tabel 1, terdapat hubungan yang bermakna pada usia, paritas, riwayat $\mathrm{SC}$, dan plasenta previa $(\mathrm{p}<0,05)$. Tidak ada hubungan yang bermakna pada riwayat kuretase dan riwayat operasi uterus lain (miomektomi) $(\mathrm{p}>0,05)$.

Tabel 1 Faktor-faktor yang berhubungan dengan plasenta akreta

\begin{tabular}{|c|c|c|c|c|}
\hline \multirow{2}{*}{ Variabel } & Kasus & Kontrol & \multirow{2}{*}{ OR } & \multirow[b]{2}{*}{$\mathbf{p}$} \\
\hline & n (\%) & n (\%) & & \\
\hline Usia & & & 3,600 & 0,009 \\
\hline$>35$ & $28(66,7)$ & $15(35,7)$ & & \\
\hline $20-35$ & $14(33,3)$ & $27(64,3)$ & & \\
\hline Paritas & & & 3,750 & 0,017 \\
\hline Multipara & $35(83,3)$ & $24(57,1)$ & & \\
\hline Primipara & $7(16,7)$ & $18(42,9)$ & & \\
\hline Riwayat SC & & & 8,000 & 0,000 \\
\hline$\geq 2$ & $30(71,4)$ & $10(23,8)$ & & \\
\hline 1 & $12(28,6)$ & $32(76,2)$ & & \\
\hline Plasenta previa & & & 4,259 & 0,030 \\
\hline Total & $38(90,5)$ & $29(69)$ & & \\
\hline Tidak total & $4(9,5)$ & $13(31)$ & & \\
\hline Riwayat kuretase & & & 6,833 & 0,114 \\
\hline Ada & $6(14,3)$ & $1(2,4)$ & & \\
\hline Tidak ada & $36(85,7)$ & $41(97,6)$ & & \\
\hline Riwayat operasi uterus lain & & & 2,050 & 1,000 \\
\hline Ada & $2(4,8)$ & $1(2,4)$ & & \\
\hline Tidak ada & $40(95,2)$ & $41(97,6)$ & & \\
\hline
\end{tabular}


Tabel 2 Luaran Maternal Plasenta Akreta

\begin{tabular}{|c|c|c|c|c|}
\hline \multirow{2}{*}{ Variabel } & Kasus & Kontrol & \multirow{2}{*}{ OR } & \multirow{2}{*}{$\mathbf{p}$} \\
\hline & n (\%) & n (\%) & & \\
\hline Lama rawat & & & 8,958 & 0,000 \\
\hline$>7$ hari & $23(54,8)$ & $5(11,9)$ & & \\
\hline$<7$ hari & $19(45,2)$ & $37(88,1)$ & & \\
\hline Transfusi darah & & & 6,400 & 0,000 \\
\hline $\mathrm{Ya}$ & $32(76,2)$ & $14(33,3)$ & & \\
\hline Tidak & $10(23,8)$ & $28(66,7)$ & & \\
\hline Rawatan ICU & & & - & - \\
\hline Ya & $8(19)$ & - & & \\
\hline Tidak & $34(81)$ & $42(100)$ & & \\
\hline Histerektomi & & & 40,00 & 0,000 \\
\hline $\mathrm{Ya}$ & $28(66,7)$ & $2(4,8)$ & & \\
\hline Tidak & $14(33,3)$ & $40(95,2)$ & & \\
\hline Ruptur buli & & & - & - \\
\hline Ya & $4(9,5)$ & - & & \\
\hline Tidak & $38(90,5)$ & $42(100)$ & & \\
\hline Meninggal & & & - & - \\
\hline Ya & $3(7,1)$ & - & & \\
\hline Tidak & $39(92,9)$ & $42(100)$ & & \\
\hline
\end{tabular}

Berdasarkan Tabel 2, didapatkan pada lama rawat $>7$ hari, transfusi darah, dan histerektomi memiliki hubungan yang bermakna dengan plasenta akreta. Tidak terdapat hubungan yang bermakna pada luaran berupa rawatan ICU, ruptur buli-buli, dan meninggal.

Tabel 3 Faktor-faktor yang dominan mempengaruhi plasenta akreta

\begin{tabular}{lcclc}
\hline \multirow{2}{*}{ Variabel } & \multirow{2}{*}{ OR } & \multirow{2}{*}{$\mathbf{9 5 \%}$ CI } \\
\cline { 4 - 5 } & & & Lower & Upper \\
\hline Usia & 0,023 & 3,431 & 1,182 & 9,955 \\
$\begin{array}{l}\text { Riwayat } \\
\text { SC }\end{array}$ & 0,001 & 6,038 & 2,145 & 16,995 \\
$\begin{array}{l}\text { Plasenta } \\
\text { previa }\end{array}$ & 0,032 & 4,785 & 1,147 & 19,963 \\
\hline
\end{tabular}

Berdasarkan Tabel 3, usia $>35$ tahun, riwayat $\mathrm{SC} \geq 2 \mathrm{kali}$, dan plasenta previa total merupakan faktor yang dominan $(\mathrm{p}<0,25)$. Ibu yang berusia $>35$ tahun akan 3,431 kali lebih berisiko dibandingkan dengan usia
20-35 tahun, 6,038 kali lebih berisiko jika memiliki riwayat $\mathrm{SC} \geq 2$ kali, dan 4,785 kali lebih berisiko jika disertai plasenta previa total.

\section{Pembahasan}

Berdasarkan frekuensi kejadian, didapatkan sebanyak 64 orang $(4,3 \%)$ ibu hamil terdiagnosa suspek plasenta akreta di RSUP Dr. M. Djamil Padang periode Januari 2016 - Desember 2017. Hal ini sesuai dengan penelitian Fitzpatrick (2012) yang mengatakan kejadian plasenta akreta sebesar $5,77 \%{ }^{3}$

Berdasarkan Tabel 1, didapatkan hubungan yang bermakna pada usia $(\mathrm{p}<$ $0,05)$ dengan plasenta akreta. Hal ini sesuai dengan penelitian Farquhar (2017) dan Koo (2012) yang menunjukkan adanya hubungan bermakna antara usia dengan plasenta akreta $(p<0,001) .{ }^{10,11}$ Usia merupakan faktor risiko yang dapat mempengaruhi kondisi uterus ibu. Pada usia $>35$ tahun, kondisi endometrium 
sudah mulai mengalami perubahan, seperti sklerosis pembuluh darah. Hal ini akan menyebabkan penurunan vaskularisasi dan mengakibatkan hipoksia jaringan. ${ }^{12}$

Terdapat hubungan yang bermakna pada paritas $(\mathrm{p}<0,05)$ dengan plasenta akreta. Hal ini sesuai dengan penelitian Fitzpatrick (2012) dan Farquhar (2017) yang menunjukkan adanya hubungan bermakna antara paritas dengan plasenta akreta $(p<0,001) .{ }^{3,10}$ Pada ibu yang multipara lebih berisiko mengalami plasenta akreta karena adanya fibrosis pada lokasi bekas implantasi plasenta pada kehamilan sebelumnya. ${ }^{13}$

Terdapat hubungan yang bermakna pada riwayat SC dengan plasenta akreta $(p<0,05)$. Hal ini sesuai dengan penelitian Morlando (2013) yang menunjukkan adanya hubungan bermakna antara riwayat SC dengan plasenta akreta $(p<0,05) .{ }^{14}$ Jaringan parut akan terbentuk pada bekas SC dan akan mengakibatkan hipoksia jaringan, sehingga trofoblas akan menginvasi lebih dalam untuk mendapatkan suplai pembuluh darah yang lebih memadai. ${ }^{15}$

Terdapat hubungan yang bermakna pada plasenta previa dengan plasenta akreta $(p<0,05)$. Hal ini sesuai dengan penelitian Jang (2011) yang menunjukkan adanya hubungan yang bermakna pada plasenta previa $(p<0,001) .{ }^{16}$ Hal ini dikarenakan pada segmen bawah uterus memiliki lapisan Nitabuch dan desidua basalis yang lebih tipis, sehingga vili korialis akan berimplantasi langsung pada miometrium untuk mencari suplai pembuluh darah yang lebih memadai. ${ }^{17}$

Tidak terdapat hubungan yang bermakna antara riwayat kuretase dan riwayat operasi uterus lainnya (miomektomi) dengan plasenta akreta $(p>0,05)$. Hal ini sesuai dengan penelitian Rac (2015) yang menunjukkan tidak adanya hubungan yang bermakna pada riwayat kuretase $(p=0,82)$ dan penelitian Tikkanen (2011) pada riwayat operasi uterus lainnya (miomektomi) $(\mathrm{p}=1,0) .{ }^{8,18}$ Penelitian oleh Fitzpatrick (2012) menunjukkan adanya hubungan yang bermakna pada riwayat kuretase dan riwayat operasi uterus lainnya (miomektomi, $\mathrm{p}<0,05)^{3}$

Berdasarkan Tabel 2, terdapat hubungan yang bermakna pada luaran maternal berupa lama rawatan $>7$ hari, butuh transfusi darah, dan histerektomi $(\mathrm{p}<0,05)$. Hal ini sesuai dengan penelitian Eskholi (2013) yang mengatakan adanya hubungan antara transfusi darah dan histerektomi pada pasien plasenta akreta. Selain itu, total lama rawatan pada penelitian tersebut memiliki rata-rata 7 hari rawatan. ${ }^{2}$

Berdasarkan Tabel 3, terdapat tiga faktor risiko yang dominan mempengaruhi plasenta akreta, yaitu riwayat $\mathrm{SC}(\mathrm{p}=0,001$; $\mathrm{OR}=6,038 ; \quad 95 \% \quad \mathrm{CI}=2,145-16,995)$, usia $(\mathrm{p}=0,023 ; \mathrm{OR}=3,431 ; 95 \% \mathrm{CI}=1,182-9,955)$, dan plasenta previa $(\mathrm{p}=0,032 ; \mathrm{OR}=4,785$; 95\% CI=1,147-19,963). Hal ini sesuai dengan penelitian Eskholi (2013) yang mengatakan bahwa faktor yang dominan yaitu riwayat SC dan plasenta previa. $^{2}$

Berdasarkan hasil penelitian ini dapat disimpulkan bahwa terdapat 64 orang ibu hamil yang terdiagnosa suspek plasenta akreta di RSUP Dr. M. Djamil Padang periode Januari 2016-Desember 2017. Terdapat hubungan yang bermakna antara faktor risiko usia, paritas, riwayat $\mathrm{SC}$, dan plasenta previa, sedangkan pada faktor risiko riwayat kuretase dan riwayat operasi uterus lainnya (miomektomi) tidak memiliki hubungan yang bermakna dengan plasenta akreta.

Riwayat $\mathrm{SC} \geq 2$ kali, usia $>35$ tahun, dan plasenta previa merupakan faktor risiko yang dominan mempengaruhi plasenta akreta. Terdapat mortalitas yang lebih tinggi pada pasien dengan suspek plasenta akreta dan hubungan yang bermakna pada morbiditas berupa lama rawat $>7$ hari, butuh transfusi darah, dan histerektomi.

\section{Daftar Pustaka}

1. Cunningham FG, Leveno KJ, Bloom SL, 
Spong CY, Dashe JS, Hoffman BL, et al. William Obstetrics. 24th ed. New York: McGraw-Hill Education; 2014. Hal. 8048.

2. Eskholi T, Weintraub AY, Sergienko R, Sheiner E. Placenta Accreta: Risk Factors, Perinatal Outcomes and Consequences for Subsequent Births. Am J Obstet Gynecol. 2013 Maret;208(3):e1-7.

3. Fitzpatrick KE, Sellers S, Spark P, Kurinczuk JJ, Brocklehurst P, Knight M. Incidence and Risk Factors for Placenta Accreta/Increta/Percreta in the UK: A National Case-Control Study. PLos One. 2012;7(12):e52893.

4. Patil SS, Puranik SS, Vishwasrao SD. Placenta Accreta Syndrome: A Rising Epidemic in Obstetrics. The New Indian Journal of OBGYN. 2018;4(2):138-40.

5. Garmi G, Salim R. Epidemiology, Etiology, Diagnosis, and Management of Placenta Accreta. Obstet Gynecol Int. 2012;2012(873929):1-7.

6. Carusi D. Placenta Accreta: Epidemiology and Risk Factors. In: Silver RM, editor. Placenta Accreta Syndrome. Salt Lake City: CRC Press; 2017. Hal. 1-12.

7. Belfort MA.PlacentaAccreta.Am J Obstet Gynecol. 2010 November;203(5):403-9.

8. Rac MWF, Dashe JS, Wells E, Moschos E, McIntire DD, Twickler DM. Ultrasound Predictors of Placental Invasion: The Placenta Accreta Index. Am J Obstet Gynecol. 2015 Maret;212(3):e1-7.

9. Committee on Obstetric Practice. Committee Opinion No. 529: Placenta Accreta. Obstetrics and gynecology. 2012 Juli;120(1):207-11.

10. Farquhar CM, Li Z, Lensen S, McLintock C, Pollock W, Peek MJ, et al. Incidence, Risk Factors and Perinatal Outcomes for Placenta Accreta in Australia and New Zealand: a Case-control Study. BMJ Open. 2017 Oktober;7(10):e017713.

11. Koo YJ, Ryu HM, Yang JH, Lim JH, Lee JE, Kim MY, et al. Pregnancy Outcomes
According to Increasing Maternal Age. Taiwan J Obst Gynecol. 2012 Maret;51(1):60-5.

12. Wardana GA. Faktor Risiko Plasenta Previa. Cerminan Dunia Kedokteran. 2007; 34(5):229-232.

13. Friyandhini F, Lestari Y, Utama BI. Hubungan Kejadian Perdarahan Postpartum dengan Faktor Risiko Karakteristik Ibu di RSUP Dr. M. Djamil Padang pada Januari 2012 April 2013. Jurnal Kesehatan Andalas. 2012;33(4):244-51.

14. Morlando M, Sarno L, Napolitano R, Capone A, Tessitore G, Maruotti GM, et al. Placenta Accreta: Incidence and Risk Factors in an Area with a Particularly High Rate of Cesarean Section. Acta Obst Gynecol Scand. 2013 April;92(4):457-60.

15. Silver RM. Placenta Accreta. In: Queenan JT, Spong CY, Lockwood CJ. Protocols for High-Risk Pregnancies: An EvidenceBased Approach. West Sussex: Wiley Blackwell; 2015. Hal. 435-44.

16. Jang DG, We JS, Shin JU, Choi YJ, Ko HS, Park IY, et al. Maternal Outcomes According to Placental Position in Placental Previa. Int J Med Sci. 201;8(5): 939-44.

17. Saleh HJ. Placenta Previa and Accreta. The Global Library of Women's Medicine.https://www.glowm.com/ section_view/heading/Placenta $\% 20$ Previa\%20and\%20Accreta/item/121Diakses pada November 2017.

18. Tikkanen M, Paavonen J, Loukovaara M, Stefanovic V. Antenatal Diagnosis of Placenta Accreta Leads to Reduced Blood Loss. Acta Obstet Gynecol Scand. 2011 Oktober;90(10): 1140-6. 